\title{
A UNIFIED REGULATORY FRAMEWORK ON A EUROPEAN INFORMATION SOCIETY: SUGGESTED BUILDING LEVELS
}

\author{
Panagiotes S. Anastasiades \\ Department of Computer Science, University Of Cyprus, \\ 75 Kallipoleos Street, P.O.Box.20537CY-1678 Nicosia, CYPRUS \\ Tel.: +357-2-892289 Fax.: +357-2-339062 \\ e-mail:panas@ucy.ac.cy URL: www.cs.ucy.ac.cy/ panas/ \\ Department of Computer Engineering and Information Systems, Polytechnic School, \\ University of Patras, \\ GR26500 Patra, GREECE, panas@ceid.upatras.gr \\ Chairman of the Permanent Scientific Committee on Social Issues of the Greek Computer \\ Society
}

\begin{abstract}
The creation of a regulatory framework, which will prepare the grounds for the transition to the Information Society, is imperative. On a European level, a great effort has already begun with the aim of laying down measures and rules which will, on the one hand, facilitate the development of new applications, and, on the other hand, act protectively in relation to the citizens' rights, and in the frame of a free and competitive environment. Every country-member is trying to lay down a framework of measures and rules towards that direction.
\end{abstract}

\section{INTRODUCTION}

Through its institutional bodies, the European Union has to perform a very significant task in relation to the emerging Information Society [1]. Both, the European Committee and the general directions [2], through proposals, studies, and research, are attempting not only to prepare the average citizen for the new electronic reality, but also to idealise in issues having to do with the social consequences which the coming of the Information Society (I.S) will bring about. 
The White bible for "development, competitiveness, and employment" [3] acclaims the transition to the I.S, as of determinant importance for the future of the European society. In all approaches, information is acknowledged not merely as a marketing product with a high added value but as the key for the new era which is emerging. Progress in technological and communicational applications annihilates distances contributing thus to reduction of the necessary movements and of, consequently, equivalent expenditures for both businesses and households.

Telecommunications and networks [4] are in the centre of our attention, since time, cost, quality, and quantity of information which will reach to the final user, depend on this sector. New opportunities and challenges are been born. However, potentiality to access the new era is not distributed equally to Europe's regions, countries, fields, businesses, and last but not least to European citizens.

The unequal distribution which is been noticed will bring significant consequences to the course of transition to the IS. For the European Union, the building of a unified regulatory framework, must constitute a factor of strengthening, social cohesion [5], blunting large technological distances, and encouraging those regions which lack in infrastructure to participate in the common effort.

It is, therefore, formally proven that the regulatory framework which is been created, does not function only as a shield in relation to the rights of citizens (passive role), but is also obliged to play the redistribution role in relation to levels of access to the technological process of evolution (active role).

In the exposition, "Europe and the Global Information Society" [6] the urgent character of enacting measures and rules which will condition our transition to the new era is emphasised.

Of course, in its attestation, the European Committee places in a higher priority the powers of the private sector considering them as the driving force of all developments [7]. In the Top Meeting, conducted in Corfu [8], the issue of creating a unified regulatory framework which will have as a basis the principles of universality, equality, and consecutiveness, was put on the table.

\section{THE EUROPEAN UNION DETERMINED THE BASIC STAGES - PRIORITIES THAT MUST RULE THE COMMON EFFORT.}

The need to elevate a unified regulatory and legal environment, with the enactment of measures and rules which are obliged to be in harmony with the modern social and economic needs, comprises the most urgent priority $[9,10]$. 
The new emerging Information Society (IS), will bring about significant changes in the way in which we perceive and experience both our working and social environment. Frameworks, everyday functions and practices, which, for decades, constituted the obvious reality around which the whole of our life revolved, are starting to look effete and unable to respond to the new electronic reality. The challenges of the new era, must become an object of attention for all citizens who will be called upon to enjoy its advantages, but also to confront the consequences which it will bring about to their life and the life of their children.

The new regulatory framework is obliged to obey to five main priorities stages.

\subsection{The Creation of a Competitive European Environment}

The first stage has as an aim. In the frames of the IS, the marketing product named "information" is passed on to the final user through networks. The quantity, quality, searching time, and consequently the cost of recovering information, depend on the breadth and potentiality of telecommunication networks.

Therefore, telecommunication infrastructures and networks acquire a significant importance since they are a key post for the new electronic era.

The new technological and communicational applications have as an aim to facilitate man at home, work, and during his daily life. The creation of a friendly in use functional environment, has as an aim to facilitate the modern man, familiarising him faster and easier with new tools and techniques.

However, although the cost of obtaining technological equipment (personal computers - peripherals - logistics, etc.) is decreasing as time goes by, the cost, quality, and capabilities of the offered telecommunication services are too far away from the role they should be playing.

In other words, although the majority of the world's citizens are excluded from the new digital era, due to a lack of infrastructure, those who are supported in terms of telecommunications are not willing to pay the high costs which arise from the invoices of telecommunication organisations. Therefore, the number of users who are actually utilising the new applications is disproportionate in relation to the expectations which were fostered for a large period of time.

What is, therefore, needed is network covering of more and more citizens and a generous reduction in invoices.

At a first glance, accomplishment of the above target essentially presupposes an increase in telecommunication organisations' expenditure for the creation of modern infrastructures on the one hand and income deductions on the other hand. Such a fact is considered as impossible in the frames of the monopoly operation of organisations. 
Expansion of the telecommunication sector to private hands, will attract large private investments, in a much attractive market for them and it will allow organisations to materialise a broad investment program in technology and infrastructures.

Expansion of networks and decrease of invoices which will come due to the intense competition which will be created, will increase spectacularly the number of those who will have the potential, technologically and financially, to make a wider use of the new applications.

For the above reasons, the creation of a competitive environment in the telecommunications sector, has been the utmost priority of the Union during the past years, since it has been Europe's big bet for the rendezvous with the IS.

The country-members, others more rapidly and others with a slower pace, have adopted in their national politics this priority, respecting not only the isolated peculiarities, but also the open challenges which they are faced with.

Today this attempt is starting to show its first written samples, since network infrastructures are moving ahead with a relatively satisfactory pace in relation to the recent past. However, even today invoices remain high. The road we have to cover is undoubtedly long.

\subsection{Issues of Interface, Standardisation, and Interoperability}

The second stage concerns issues of interface, standardisation, and interoperability [11] The prevailing situation in the electronic communicational applications sector is characterised by the continuous change of facts in both their logistic and material parts which are used.

Digitalisation, gradual abolition of phenomena coming from the confrontation of restrictions in capacity, ambiguity of technological distinctions between on-line and wireless communication, and bridging the gap between traditional means of transmitting voice, facts, graphics, and music, will lead to a fundamental reassessment of the regulatory framework's role and the field of action of rules which govern the sector of telecommunication specifications.

The creation of numerous networks, which will apply to various markets and types of users, is already a priority for many organisations of the public and particularly the private sector, who are developing a huge number of applications with receivers the final users, irrespective of their country of origin.

One of the dangers which has been traced down timely, is the development of numerous networks with technological creational tools, or even application logistics and services incompatible between them.

In this case, technological applications will remain incomplete in relation to the targets which have been posed, since no network will be able to get 
connected with the rest, if the equivalent anticipation does not exist and their design is not governed by the principles of interoperability of services and network interface.

In other words, the ability to send an electronic message to someone else, irrespectively of the network that a user is utilising, who at that moment is located in a different from him network (interoperability of services).

Moreover, to have the ability to access, through the network to which the user is connected, any other network which he wishes to (network interface).

If such a thing is not achieved, it will result to the existence of local or district networks which will be isolated and consequently their utility will be marginal, having as a consequence their inefficient operation, waste of human sources and investments, their low demand, and finally their marketing and operational failure.

This presupposes standardisation in the technology of network construction and of relevant technological applications. Therefore, standardisation in the technology of information and politics of communications obtains a substantial significance and content with the aim of rising the potentiality of responding to increased demands in the market [12].

Technological infrastructure, in a continuously more dense body of networks and application and equipment services of general use, will demand for its completion enormous sources. These costly efforts have as an aim the harmonisation of various sectors in this complex system, so that they can comprise a unified whole, handy and operational to the final user.

In order to achieve this, what are needed are clear agreements and rules, named models, which will play a substantial role in the future, since they will contribute to the avoidance of breaking into pieces and to the better use of networks and services.

\subsection{Human Existence and Intellectual Property}

The third stage concerns issues having to do with human existence and intellectual property.

Dealing with intellectual rights [13], confidentiality of private life, but also with electronic and legal protection [14], are matters within a high priority.

The largest part of information transmitted in all kinds of networks is given free, a fact which is judged as positive since it facilitates access to even more of those interested in information.

However, information with added value does exist which is the product of intellectual toil. This is, in other words, the intellectual property of an individual or of organised team work and as such it must be protected, according to the practice of intellectual property rights. 
In the emerging era of effusion in technological applications, of easy access to sources of information via networks, issues such as the protection of intellectual property obtain a totally different content.

The existing statutory framework seems to be unable to deal with the new facts, since it is based on views and structures which have been surmounted by life.

For instance, how is it possible for the statutory framework which exists today to cope with the general violation of intellectual rights which is occurring more and more frequently on the Internet? [15]

How can an artist be protected, when the product of his toil is available illegally, without his permission, in a particularly low price on the Internet?

From the moment that everything today is traded under the form of digitalised information, through the net, the meaning and significance of control imagines as particularly ambiguous, since no framework for its application does exist.

Intellectual rights, apart from the moral aspect of this issue, comprise an important factor for the development of a competitive European industry, particularly in the information sector.

Protection of creativity and originality are high priority issues and must be settled in the frame of such regulations which will not create bureaucratic disfunctions and technical character obstacles and silts.

In the frame of a global market, in which information and intellectual goods will be broadly traded, common rules of commitment must be agreed. It is clear that, parallel to technological progress, regular deliberations with all the interesting parties, suppliers and user teams, will be needed.

The development of new technologies has given a new dimension to the concept of information since the elaboration and management of personal details is now feasible in the form of electronic facts, vocal and visual. The development and use of such applications bring up extremely sensitive issues such as, for example, communication, transference, social and political behaviour of citizens. The absence of safety valves via the legislative venue, will become a factor of instabilisation having as a result the appearance of lack of trust from behalf of the citizens with unforeseen dimensions.

It is, therefore, necessary to take all the necessary measures, in which interborder control of the new technologies and services is likely to be included, a fact which may impede the free circulation of a broad spectrum of services, but is judged as absolutely necessary since protection of private life is an utmost commodity. Although the fact that a part of information is given free with no charge, there are quite a few times when specific information and services are priced according to the importance they have for consumers, from whom only those who pay the relevant price which as been determined will have the right to access. Moreover, depending on the 
type and level of trust on the provided information, gradings for the level of access for those interested and users in general, do exist.

This is achieved through electronic protection (cryptography) and especially in this case we have to say that access control is very important. Global harmonisation in the standardisation of cryptography systems, is thought to be particularly important, since it would encourage the market to adopt a more fair and open competition for the benefit of consumers and those who supply services.

Cryptography gains particular importance for the electronic market, which needs absolute guarantees concerning authenticity of signatures and texts, irreversible timing, transaction date and international legal recognition. Its contribution to the protection of high security details, personal details, etc. will be noteworthy.

Although the attempted efforts, it is a fact that nobody feels the necessary security since the temporary inability to attain perfection in cryptography systems fosters electronic piracy, which has managed to penetrate even into the files of secret services. The creation of a legislative framework which will secure producers and consumers from electronic piracy, in combination with the overcoming of technical difficulties which are still noticed, will open new pathways to services and technological applications. The legislative framework must offer equal conditions of security and development of cryptographic services [16].

The many-faceted development of the electronic market [17],creates a new consumer belief and behaviour environment. Protection of consumers' rights has come into the European Union's agenda.

It is a fact that issues concerning human existence and dignity are at the same time the largest danger spots in the modern era. If human creativity is sacrificed to electronic piracy [18] and illegal profit, and personal security is threatened by electronic crackers, without anyone being able to interfere, the result will be disappointing if not dangerous. The creation of a regulatory framework for such kind of issues rises into an urgent priority.

We cannot close our eyes to the future and confront the new dangers with the current old-fashioned weapons, because such a thing will result to the dominance of a new technological Babel which will lay flat everything in its way. Nor can everything be left uncontrolled in the name of a general liberation which characterises our times.

What we, as citizens, must do is impose the values and perceptions of social justice to the new era, of which the consumer models and concerns it stands for, are eventually aiming to the package and not to the content, the consumer and not the human, the market and not society.

The enactment of measures for the protection and security of human existence must be consistent since it is obliged to progress parallel to technological progress and its achievements. 
Even in the USA where the market and its forces have been deified and any kind of interference from behalf of the government is not looked at with a good eye, specific measures have been taken towards this direction.

We are mentioning indicatively the enactment of measures which contribute to the security of information: "Foreign corrupt practice act (1977), The counterfeit access device (1984), Electronic communication privacy \& The computer security (1986), etc.

\subsection{The Global Dimension of the Information Society}

The fourth stage concerns the global dimension of the IS and especially the development of new satellite systems and the securing of a balanced participation in them. The global dimension of the IS is directly related to developments in the area of satellite communications [19]. Progress in the sector of satellite communication is an investment of strategic importance for the IS [20], since the more and more increasing demands which are been created make necessary the development of informational structures in global interface, unlimited capacity, and quick timing in responding.

Since the time that the first geostationery communication satellite, "Early Bird", transferred above the Atlantic three hundred telephone networks with the aim of connecting four European countries with the USA, merchandising satellite communications have acquired an experience of 25 years. The international organisation of telecommunication satellites, Intelsat, provides today the transmission of $2 / 3$ of transcontinental phone calls

The equivalent European satellite system Eutelsat, is utilised mainly for the purposes of transmitting television programmes. The satellite communication systems consist of three sections:

The fixed section of upward connection; in other words, the transmission channel of information from one powerful terrestrial station towards the satellite.

The space station; in other words, the satellite transmitters which transmit the information towards Earth.

The fixed section of downward connection; which is determined in the frame of services, such as telecommunications from one point to another, television broadcasting from one place to numerous other places, etc.

Satellite communication having the advantage of broad geographical coverage, is used today for television broadcasting and telecommunications.

Pilot programmes of expanding its use for the support of other applications, in combination with the almost minimal cost which is needed for terrestrial support, will totally free the possibility of communication and planetary interface.

Europe must undertake a much more active and conscientious approach to the satellite communication sector[21]. Under the combined pressure of 
rapid technological progress, gradual liberation, and convergence of the telecommunications and transmission sectors, developments in the sector of satellite communication are of significant strategic and merchandising importance. The new demands which arise for the IS, call for high quality access and existence of network infrastructures. Therefore, global satellite infrastructures will form a significant part of the international economic system.

Moreover, satellite communication systems are been developed into a significant tool for the support of businesses during periods of peace, and space systems in general have an eminent defensive importance. In addition, geographical coverage of space infrastructures, favours the strengthening of social and economic cohesion, through the connection of remote and less developed regions. A possible cohesive communications and information industry is of high economic and political significance for Europe.

It will be a crucial influence factor for the development and spread of new applications in the IS and for the geographical distribution. The USA have the lead in satellite communications of international coverage especially in the sector of Satellite Personal Communications (S-PCS) and advanced multimeans of a broad spectrum.

If Europe does not react in a co-ordinated manner, there is a high danger of been excluded from this much promising part of the market (services and equipment). Controlling the design of the space sector is essential for the maintenance of the design of terminals and the supply of services from one corner to the other.

A basic precondition for the marking of Europe as a significant factor in space, is the achievement of successful merchandising services and applications. The takings which arise in various sectors of the market (satellites, terminals, and services) from the pioneer satellite personal communication system and the advanced satellite systems of a broad spectrum, are expected to reach the amount of 400 billion US dollars in the next ten years. The Satellite Personal Communications System (S-PCS) will offer vocal services of low flow facts, in cheap pocket-size terminals, and low Earth Orbits and satellite constellations.

From the 17 such systems which exist today, all apart from one, come from the USA, although only a limited number is expected to be viable.

Although the European industry participates in these programmes, none of these systems has gained a European leading role. The development of advanced multimeans of a broad spectrum, in combination with the use of satellite systems, create unlimited possibilities, since they offer the potential of high quality access to the user with low cost interactional terminals. These systems are expected to play a significant role for the advanced access to the Internet. The majority of the proposed systems are of American origin.

From the 16 proposed American systems, all apart from two, have as a base geostational constellations. From these, the Teledesic system proposes a 
constellation with an orbit close to Earth, with 840 satellites and a cost of nine billion US dollars, whereas Motorola announced the M-STAR programme costing 1,6 billion dollars.

The European reaction to the numerous American systems, although delayed, was introduced at the end of 1995.Four entities have shown up to now an interest in the issue and they have held frequencies and orbital positions in the $\mathrm{Ka}$ spectrum.Despite the above, the inability to create a critical mass at the level of initiatives, and of co-operation between the private and public sector which would grant the necessary trust to financial markets, have limited for the time being the prospect for such European cooperations.The situation is even worse in the case of S-PCS, where there is no European proposal at all.

Therefore, despite the huge efforts during the past 30 years, the European equipment and services industry, has not reached the point which would allow it to gain the position in the space marketing sector which is necessary in order to support the leading ambitions of the European Union.

The potential consequences of this prospect must not be underestimated, because the leaders will have an obvious advantage in the market.

\subsection{The Mass Media and Audio-Visual Sector.}

The audio-visual sector has experienced during the last years an enormous progress, offering significant services to the broad consumer society in the sectors of information and entertainment [22]. Television and radio, have been, for quite a few years now, an inseparable part of our 'household culture', although they have been through heavy criticism for both the content of their programme, and the more general consequences which this brings to the broader social layers. It is true that the electronic means of communication have contributed largely to the direct informing of citizens and specifically of those who live in remote areas, breaking the isolation for the outer world.

Our world has become smaller, since we finally have had the capability to 'travel' the news in a few minutes. Millions of people around the world, had the opportunity to follow live important and trivial events, to meet, through motion, sound and vision, other people, different cultures, customs and traditions.

Many rushed, when with the spread of electronic means, they hurried to foresee the end of printed journalism. Contrary to the predictions, newspapers and magazines not only survive, but they also possess a significant part of the mass media industry.

The press, unable to play the game of timely information since in this sector television and radio have had the unquestionable technological superiority, have proceeded to two tactical moves. 
The first is centred around the fact that newspapers and magazines shift their attention to the analysis of events and not to simply recording them, as television is obliged to do due to limited television time.

The second is located in the intense breaking into pieces of material having as a criterion the readers (target group)to which the publication appeals to. Therefore the market has been flooded by publications for the youth, women, sports, entertainment, education, new technologies, nutrition, home decoration, sales, stock market, covering almost all human activities of social layers and thematic chapters. Television is hard-moving in this sector since from its nature it is obliged to cover all interests spherically.

The creation of thematic TV stations, music, sports, etc., did not prosper at least in the small and average markets like the Greek, because it was not possible to create the critical mass, the minimum, in other words, number of consumers, which would allow them to have the takings needed in order to survive.

Therefore, the press is a fine example in relation to the way in which a traditional sector can creatively adjust to the new developments, even when these seem particularly gloomy for its future.

The spread of mass media, did not only create numerous employment positions all over the world, but it has also formed a specific power block of those people or the interests of those who have controlled information on a national or regional level.

This phenomenon has spread largely, since the control of the flow and quality of information, is what moulds conscience and shapes views. The mass media do not only convey information, but, through the passage of time, they have grown to become the most powerful moulders of public opinion. If in the past it was thought as natural for a political party to have under its influence a mass media product, today the opposite does not provoke the common sense of anybody.

The interweaving of mass media owners, production means, and political power enactment means (i.e. political parties), is a source of political microbes, particularly resistant and dangerous for the nature and operation of a democratic constitution. Let us focus, however, our attention to the operation of television, attempting a brief historical account which will prove to be particularly useful for what follows.

Television, as technology, combines mobile picture - in the beginning black and white, then colour - and sound. In its first steps under the supervision of the government, the hours of broadcasting were minimal and tele-recorded programmes were limited to news, documentaries, while entertainment shows slowly slowly started to appear. The main characteristics of television, in its first steps, where the public ownership status quo, the tele-recorded programmes, the few hours of operation and the small number of people who had the potential to purchase it. A precondition for the purchase of this amazing for that period of time means was the 
purchase of equipment - device and aerial - and geographical installation with the capacity of TV reception signals.

Therefore, only the high income layers in specific geographical areas of the country, usually in the capital cities of counties, had access to television. The placing of numerous relay stations and progress in television production technology had as a result the expansion of geographical coverage and a fall in the price of television sets. Every family was able to purchase its own television, which evolved from a forbidding high technology device to an ordinary product of broad consuming. Programmes were multiplied, while for the first time the term 'live broadcasting' was introduced to our daily life, a term which gave a highly added value to television, since this mean, apart from picture and sound, added to its treasury the dimension of real time.

"Canned" television gave its place to a new communications means, which exploited as much as possible the real dimension of time and was bound to evolve into a window to the world or more simply into an active information network. The Greek television experience is particularly traumatic, if we take into account the fact that its first steps were made during the dictatorship period and its coming of age coincided with the illegal transmission of satellite programmes in the second largest city of Greece and the operation of private TV stations without a licence, having as a result the creation of an uncontrolled situation which very rightly has been characterised as the modern television Babel.

Pluralism of views, objective information and entertainment of television viewers, comprised the basic programming positions of private television. The course we have covered until today is judged as satisfactory to derive to conclusions and evaluate in a cool and calm manner a long and fully intense course. Today the mass media sector is going under deep structural changes. Large associations are expanding their activities from printing and traditional transmission to electronic production and digital television.

The Information Society facilitates the production and distribution of more specialised logistics, expanding by this way the spectrum of information services. The integration of television and the computer will be a milestone for the new electronic reality.

Multimedia [23], have flooded the markets, with applications particularly in the sectors of education and entertainment. A simplified definition for the multimedia, is summarised to the operational planning of the communicational potentials of television - extending to the video- in combination with the trait of retroactional relationship that the computer has to offer. In today's reality, multimeans are used mainly as synonymous to electronic books which are available in the form of CD-ROM, combining music and speech with text and picture in a totally retroactional environment. The fundings needed for such investments, presuppose businesses with a large economic surface. 
The construction of a regulatory framework in the audio-visual sector, must include the restoration of law and order in the issue of frequencies, the enactment of regulations for the protection of the listener - viewer, the media ownership status quo in order to avoid the creation of monopoly situations, and finally preparation of the media and particularly television, for the new era which is coming.

\section{CONCLUSIONS}

The coming of the Information Society will bring significant changes to the whole of human activities, from employment and scientific research to everyday life and entertainment of the modern man. Both as content and operation as well as structure, the Information Society is not an abstract notion nor something vague which is traced in the distant future and will concern people of the letters and science.

The new emerging society will be based on modern information and communication technologies, which in the form of operational applications and electronic services, have already come into our life for good, giving to all of us a first taste on our digital future. Electronic mail, tele-conferences, electronic transference of facts, are all simple examples of services, which today form an inseparable part of everyday reality, in the areas of employment, education, applied research, etc. The functional infiltration of the new services to the whole of human activities is unprecedented and accompanied by the huge changes it bears. The breadth of these changes is not limited to the easier use of the new technology and the more efficient performance of professional activities, but it also creates the conditions which literally overturn facts in the areas of production, management, sales, organisational structure, and finally businesslike behaviour.

Changes of a similar or larger intensity, will also come in the areas of education, health, marketing, consuming, employment, entertainment, surpassing any existing branch, geographical, and production peculiarity. The use of the term "Information Revolution" is not an exaggeration or generalisation, something which tends to happen in our era. The use of the term "revolution" is judged as imperative, since the new electronic reality marks tremendous changes to the whole of our lives, work, education, entertainment, everywhere. In an obvious period of time nothing will remind us of our current way of living, since the rapid introduction of new technological and communicational applications will bring the neglecting of the current social and employment model.

The industrial society is closing its circle, inheriting many of the new era's problems. Evaluation of its contribution to the course of human evolution, must in any case include the fact that it has fed us with scientific and technological tools capable of not only anticipating but also preparing the new era. 


\section{References}

1. European Commission, European Commission, Communication from the Commission to the Council, the European Parliament, the Economic and Social Committee and the Committee of the Regions on 'Europe at the forefront of the global information society : rolling action plan', COM (96) 607

2. FinalCommunication from the Commission to the Council, the European Parliament, the Economic and Social Committee and the Committee of the Regions on 'Europe at the forefront of the global information society : rolling action plan', COM (96) 607 final

3. European Commission, Growth, competitiveness, employment The challenges and ways forward into the 21 st century White Paper, COM ( 93 ) 700 final.

4. European Commission, Green Paper on the convergence of the telecommunications, media and information technology sectors, and the implications for Regulation Towards an information society approach ( presented by the Commission ), COM ( 97) 623 final

5. European Commission, Communication from the Commission to the Council and the European Parliament: cohesion and the information society.pp 9.COM(97)7/3,Brussels

6. European Commission, Communication from the Commission to the Council, the European Parliament, the Economic and Social Committee and the Committee of the Regions on 'Europe at the forefront of the global information society : rolling action plan', COM (96) 607 final.

7. European Commission, Proposal for a Council Decision on measures of financial assistance for innovative and job - creating small and medium - sized enterprises (SMEs) The growth and employment initiative ( presented by the Commission ), $\operatorname{COM}(98) 26$ final

8. European Commission, Communication from the Commission to the Council, the European Parliament, the Economic and Social Committee and the Committee of the Regions The information society : from Corfu to Dublin The new emerging priorities Communication from the Commission to the Council, the European Parliament, the Economic and Social Committee and the Committee of the Regions on 'The implications of the information society for European Union policiesPreparing the next steps', COM (96) 395 final.

9. European Commission, Commission communication on the protection of individuals in relation to the processing of personal data in the Community and information security Proposal for a Council Directive concerning the protection of individuals in relation to the processing of personal data Draft resolution of the representatives of the Governments of the Member States of the European Communities meeting within the Council Commission declaration on the application to the institutions and other bodies of the European Communities of the principles contained in the Council Directive concerning the protection of individuals in relation to the processing of personal data Proposal for a Council Directive concerning the protection of personal data and privacy in the context of public digital telecommunications, COM (90) 314 final.

10. European Commission, Communication from the Commission to the Council, the European Parliament, the Economic and Social Committee and the Committee of the Regions Illegal and harmful content on the Internet, COM (96) 487 final.

11. European Commission, Communication from the Commission to the Council and the European Parliament: Standardization and the global information society COM(96)359, 24/7/96 Brussels,pp2-3

12. European Commission, Green Paper on the convergence of the telecommunications, media and information technology sectors, and the 
implications for Regulation Towards an information society approach ( presented by the Commission ), COM ( 97) 623 final.

13. European Commission, Proposal for a European Parliament and Council Directive on the harmonization of certain aspects of copyright and related rights in the Information Society ( presented by the Commission), COM (97) 628 final.

14. European Commission, Opinion of the Commission pursuant to Article $189 \mathrm{~B}(2)(\mathrm{d})$ of the EC Treaty, on the European Parliament's amendments to the Council's common position regarding the proposal for a European Parliament and Council Directive concerning the processing of personal data and the protection of privacy in the telecommunications sector, in particular in the integrated services digital network (ISDN) and in the public digital mobile networks, amending the proposal of the Commission pursuant to Article 189A(2) of the EC Treaty, COM (97) 94 final.

15. European Commission, Communication from the Commission to the Council and the European Parliament Internet Governance Management of Internet names and adresses Analysis and assessment from the European Commission of the United States Department of Commerce White paper, COM (98) 476 final.

16. Dam,K.D,.Cryptography's role in securing the information society. National Academy Press..Vol. 1,2, 1996

17. European Commission, A European Initiative in Electrnic Commerce COM(97) 157

18. FBI Press Room - Congressional Statement - 1998 - Cybercrime, Transnational Crime, and Intellectual Property - Neil J. Gallagher. Available on line on [http://www.fbi.gov/congress/congress98/gallagher.htm]

19. European Commission, Communication from the Commission to the Council, the European Parliament, the Economic and Social Committee and the Committee of the Regions EU Action Plan : Satellite communications in the Information Society, COM (97) 91 final.

20. European commission, status report on European union telecommunication policy, dg xiii, Brussels 26-1-1998 (pp40).

21. European Commission, Communication from the Commission to the Council, the European Parliament, the Economic and Social Committee and the Committee of the Regions EU Action Plan : Satellite communications in the Information Society, COM (97) 91 final.

22. Larose, $\mathrm{R}$, Communication media in the information society. Wadsworth Pub Co,1997.

23. European Commission, Amended proposal for a Council Decision adopting a multi-annual Community program to stimulate the development of a European multimedia content industry and to encourage the use of multimedia content in the merging information society (INFO 2000) ( presented by the Commission pursuant to Article 189A (2) of the EC Treaty), COM (96) 188 final. 